\title{
Genetics of oviposition-site preference in Drosophila tripunctata
}

\author{
John Jaenike
}

Department of Biology, University of Rochester, Rochester, New York 14627, U.S.A.

\begin{abstract}
A survey of 175 isofemale strains from seven populations of Drosophila tripunctata showed that the preferences of females for mushrooms versus tomatoes as oviposition sites follow an approximately normal distribution among strains, as would be expected if this behaviour were governed by many genes with small, additive effects. However, crosses among several strains revealed the existence of autosomal genes with dominance and interaction effects having substantial influence on oviposition-site preference. Despite the apparent genetic complexity of this behaviour, it was found that at least one locus affecting this preference is linked to the autosomal gene encoding the enzyme aconitase, thus encouraging the belief that it may eventually be possible to study the molecular and developmental basis for this evolutionarily important behaviour.
\end{abstract}

\section{INTRODUCTION}

Previous estimates of insect diversity (e.g., Williams, 1960) now appear to have been off by as much as an order of magnitude (Erwin, 1982, 1983). The extraordinary number of insect species is due largely to the diversity of just four orders, the Coleoptera, Diptera, Hymenoptera, and Lepidoptera, many of whose members feed as Iarvae on discrete, patchy resources (hosts) selected by ovipositing females. Because related species of insects often differ in their host utilisation, it follows that evolutionary changes in host specificity have accompanied and perhaps contributed to the diversification of insects. While much work has focused on the physiological adaptations required to feed on various resources (e.g., Rosenthal and Janzen, 1979), there is growing evidence that host specificity is determined to a significant degree by host-seeking behaviour, particularly that of ovipositing females (Jermy, 1984; Miller and Strickler, 1984).

While the existence of intraspecific genetic variation for breeding-site selection (e.g., Wasserman and Futuyma, 1981; Tabashnik et al., 1981; Jaenike and Grimaldi, 1983) indicates the potential for evolutionary shifts in resource use, an understanding of the mode of inheritance of such variation may shed light on how such shifts can occur. For instance, the probability of occurrence of a rapid host shift and consequent speciation may be a function of the genetic basis for variation in resource use (see, for example, the genetic transilience model of Templeton, 1980).

Crosses carried out between individuals from different, genetically isolated populations (Carson and Ohta, 1981; Leslie and Dingle, 1983), "host races" (Knerer and Atwood, 1973), or species (Huettel and Bush, 1972) often show a pattern of genetic dominance for a particular oviposition behaviour. Such experiments, however, shed no light on the nature of genetic variation within populations, on which microevolutionary changes depend. Reported on here is a series of experiments on the genetics of oviposition-site preference in Drosophila tripunctata, involving crosses among flies descended from a single natural population.

\section{METHODS AND MATERIALS}

Most of the results reported here are based on crosses among four isofemale strains of $D$. tripunctata descended from flies captured in the Great Smoky Mountains National Park. Strains S64 and S74 were started from females caught on August 11,1981 at $450 \mathrm{~m}$ elevation near the Little Pigeon River. Strains GFS-B9 and GFS-M10, abbreviated 
hereafter as B9 and M10, were collected on June 19, 1984 near Le Conte Creek at about $750 \mathrm{~m}$ elevation. The two sites are about $10 \mathrm{~km}$ apart.

Data are also reported, in a preliminary way, on the oviposition-site preferences and electrophoretic variation in 175 isofemales strains of $D$. tripunctata derived from flies collected in June 1984 from Clermont, Florida; Gainesville, Florida; Buxton, North Carolina; Chesapeake, Virginia; and three sites in the Great Smoky Mountains National Park. These strains were maintained by sib mating for the first three generations in laboratory culture in order to increase the ratio of a mongto within-strain genetic variation.

In addition to these surveys, four experiments on oviposition-site preference involving crosses between isofemale lines were carried out:

Experiment 1 (1983). This involved the production of parental, $F_{1}, F_{2}$, and backcrossed flies to obtain flies with various combinations of S64- and S74-derived genomes. All generations were produced and tested contemporaneously. This experiment provided data on maternal/cytoplasmic, X-chromosomal, and autosomal effects on oviposition behaviour.

Experiment 2 (1983). This experiment on strains S64, S74, and $F_{2}$ derived from crosses between them investigated the genetic correlation between oviposition behaviour in the laboratory and settling behaviour in the field, and has been reported elsewhere (Jaenike, 1986). Data from it are relevant here to the question of dominance and the existence of modifier loci.

Experiment 3 (1984). Strains S64 and S74 were crossed reciprocally and the oviposition behaviour of $F_{1}$ progeny was studied to see if there were maternal or cytoplasmic effects on oviposition behaviour.

Experiment 4 (1985). This was designed to study the linkage between a locus affecting oviposition behaviour and the gene that encodes the enzyme aconitase. The oviposition-site preference and aconitase genotype were determined in $\mathrm{F}_{2}$ flies derived from crosses between strains B9 and M10, which differ in both respects.

Prior to the tests of oviposition behaviour, all strains were maintained at about $20^{\circ} \mathrm{C}$ on food made from Instant Drosophila Medium (Carolina Biological Supply) to which a piece of fresh Agaricus bisporus (commercial mushrooms) and a dental cotton roll (to provide pupation sites) had been added. Flies whose oviposition behaviour was to be tested were raised on this medium at $22-23^{\circ} \mathrm{C}$; upon emergence of adults, flies were transferred to Instant Drosophila Medium without mushrooms. Larval food has no detectable effect on oviposition-site preference in Drosophila (Jaenike 1982).

Oviposition tests were initiated with flies that were 6 to 8 days old. In all cases but one, the oviposition behaviour of individual inseminated females was studied. For the survey of the 175 isofemale strains, 10 replicate groups of 10 males and 10 females of each strain were studied. Flies were placed in petri dishes, each of which contained one slice of gelled medium prepared from commercial mushrooms and one slice of gelled medium prepared from salt-free tomato juice (for recipes, see Jaenike 1986). The plates were kept for 24 hours (for the flies tested in groups) to 48 hours (for the flies tested individually) at a temperature of $22-23^{\circ} \mathrm{C}$ and a $14: 10$ light-dark cycle. At the conclusion of an oviposition test, the plates were frozen until the eggs were counted. In each experiment and in the general survey, all flies were tested simultaneously to minimise variation due to media preparation or environmental conditions.

Data on the fraction of eggs laid on mushrooms, $P_{m}$, were analysed with SAS programmes (SAS Institute Inc., 1982). Parametric tests were carried out on percentages transformed to angles, because such transformed data more closely approximated normal distributions. Nonparametric tests were used when the data were clearly not normally distributed. For ease of comprehension, all data are presented here as untransformed fractions of eggs laid on mushroom medium.

\section{RESULTS AND DISCUSSION}

\section{Quantitative variation}

The survey of behaviour in the 175 isofemale strains collected in 1984 revealed highly significant quantitative differences among them in oviposition-site preference. Analyses of these data and a more detailed discussion of them will be presented elsewhere. For purposes of this paper, it is sufficient to note that the preferences of strains for mushrooms versus tomatoes as oviposition sites closely approximates a normal distribution (fig. 1; Kolmogorov-Smirnov $\quad D=0.043, \quad P>0.2)$. Neither in the sample of all 175 strains combined nor in the samples from individual populations, which do vary significantly from one another, is there any evidence that the distribution of oviposition-site preferences is anything other than 


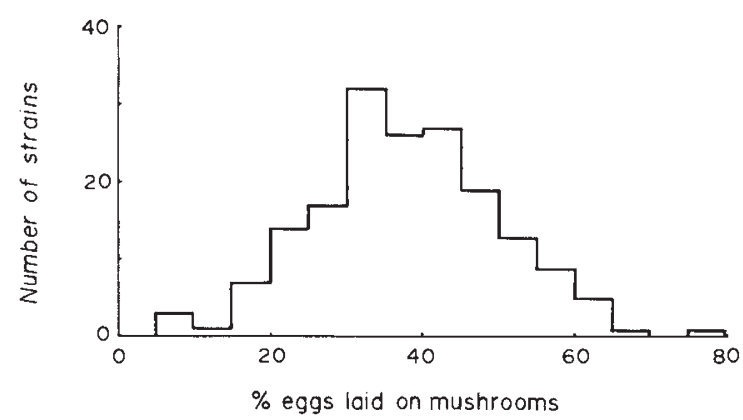

Figure 1 Distribution of oviposition-site preference, in a choice between mushrooms and tomatoes, of 175 isofemale strains derived from flies collected from seven populations of D. tripunctata.

unimodal. The remainder of the results are concerned with uncovering some of the causes of this quantitative variation among strains.

\section{Maternal effects}

Strains S64 and S74, which consistently differ in oviposition-site preference (Jaenike, 1985, 1986, and below), were crossed reciprocally in Experiment 1 to determine if there were cytoplasmic or maternal effects on egg laying behaviour. In these tests, the $F_{1}$ females derived from the cross $S 64 \sigma^{*} x$ S749 differed somewhat in oviposition behaviour from females produced by the reciprocal cross (table 1), but the difference was not significant and was in the direction opposite that expected if there were cytoplasmic or maternal effects. The possibility of such effects was tested again in Experiment 3 , and in this case offspring from the crosses $S 64 \delta \times$ S74 $q$ and $\mathbf{S} 748 \times$ S64 $q$ laid, respectively, an average of 39 per cent \pm 2 per cent $(n=87)$ and 41 per cent \pm 2 per cent $(n=99)$ of their eggs on mushrooms; these means are not significantly different $(t=0 \cdot 51,184 \mathrm{df}, P>0 \cdot 5)$. Thus, maternal/cytoplasmic effects cannot account for the large difference in oviposition-site preference between these two strains.

\section{X-Chromosomal effects}

Experiment 1 involved crosses between S64 and S74 to obtain $F_{1}, F_{2}$, and various types of backcrossed flies. A number of categories of females were produced that carried similar complements of autosomal genes but that differed by 50 per cent in the origins of loci on the $\mathrm{X}$ chromosome (table 1). There are three such pairs of groups--E and $F, G$ and $H$, and $\mathrm{K}$ and $\mathrm{L}-$ and in none of them do the two groups differ significantly in oviposition behaviour.

In two other experiments (numbers 2 and 4), involving reciprocal crosses between strains S64 and S74, and between B9 and M10, respectively, $\mathrm{F}_{2}$ females were obtained that differed by 50 per

Table 1 Oviposition-site preferences of S64, S74, and flies derived from crosses between these strains in Experiment 1. Data presented for females that laid $>10$ eggs

\begin{tabular}{|c|c|c|c|c|c|c|c|}
\hline \multirow[b]{2}{*}{ Category } & \multirow[b]{2}{*}{ Parents } & \multirow{2}{*}{$\begin{array}{l}\text { Offspring } \\
\text { designation }\end{array}$} & \multirow[b]{2}{*}{$n$} & \multirow[b]{2}{*}{$P_{m}^{*}$} & \multirow[b]{2}{*}{ Std. dev. } & \multicolumn{2}{|c|}{$\begin{array}{l}\% \text { S64-derived genes } \\
\text { in female offspring }\end{array}$} \\
\hline & & & & & & $\mathrm{X}$ chromosomes & Autosomes \\
\hline Parental strains & $\begin{array}{l}\text { S64 } \\
\text { S74 }\end{array}$ & $\begin{array}{l}\mathrm{A} \\
\mathrm{B}\end{array}$ & $\begin{array}{r}100 \\
76\end{array}$ & $\begin{array}{l}0 \cdot 32^{\mathrm{a}-\mathrm{c}} \\
0.66^{\mathrm{e}}\end{array}$ & $\begin{array}{l}0 \cdot 15 \\
0 \cdot 25\end{array}$ & $\begin{array}{r}100 \\
0\end{array}$ & $\begin{array}{r}100 \\
0\end{array}$ \\
\hline$F_{1}$ & $\begin{array}{l}\mathrm{A} 0^{*} \times \mathrm{B} q \\
\mathrm{~B} 0^{*} \times \mathrm{A} q\end{array}$ & $\begin{array}{l}\mathrm{C} \\
\mathrm{D}\end{array}$ & $\begin{array}{r}19 \\
135\end{array}$ & $\begin{array}{l}0 \cdot 25^{\mathrm{a}} \\
0 \cdot 37^{\mathrm{a}-\mathrm{d}}\end{array}$ & $\begin{array}{l}0 \cdot 15 \\
0 \cdot 18\end{array}$ & $\begin{array}{l}50 \\
50\end{array}$ & $\begin{array}{l}50 \\
50\end{array}$ \\
\hline $\mathrm{F}_{2}$ & $\begin{array}{l}\mathrm{C} d \times \mathrm{D} q \\
\mathrm{D} 0^{*} \times \mathrm{C} q\end{array}$ & $\begin{array}{l}\mathrm{E} \\
\mathrm{F}\end{array}$ & $\begin{array}{l}57 \\
30\end{array}$ & $\begin{array}{l}0 \cdot 33^{\mathrm{a}-\mathrm{c}} \\
0 \cdot 23^{\mathrm{a}}\end{array}$ & $\begin{array}{l}0 \cdot 22 \\
0 \cdot 19\end{array}$ & $\begin{array}{l}25 \\
75\end{array}$ & $\begin{array}{l}50 \\
50\end{array}$ \\
\hline $\begin{array}{c}\text { Backcrosses } \\
\text { to } \mathrm{S} 64\end{array}$ & $\begin{array}{l}\mathrm{C} \sigma \times \mathrm{A} q \\
\mathrm{D} \sigma \times \mathrm{A} q \\
\mathrm{~A} \sigma \times \mathrm{C} q \\
\mathrm{~A} \sigma \times \mathrm{D} q\end{array}$ & $\begin{array}{l}\mathrm{G} \\
\mathrm{H} \\
\mathrm{I} \\
\mathrm{J}\end{array}$ & $\begin{array}{l}83 \\
47 \\
94 \\
75\end{array}$ & $\begin{array}{l}0 \cdot 31^{\mathrm{a}-\mathrm{c}} \\
0 \cdot 29^{\mathrm{a}-\mathrm{c}} \\
0 \cdot 32^{\mathrm{a}-\mathrm{d}} \\
0 \cdot 28^{\mathrm{a}, \mathrm{b}}\end{array}$ & $\begin{array}{l}0 \cdot 19 \\
0 \cdot 17 \\
0 \cdot 24 \\
0 \cdot 16\end{array}$ & $\begin{array}{r}50 \\
100 \\
75 \\
75\end{array}$ & $\begin{array}{l}75 \\
75 \\
75 \\
75\end{array}$ \\
\hline $\begin{array}{l}\text { Backcrosses } \\
\text { to } 574\end{array}$ & $\begin{array}{l}\mathrm{C} 0 \times \mathrm{B} q \\
\mathrm{D} 0 \times \mathrm{B} q \\
\mathrm{~B} \delta \times \mathrm{C} q \\
\mathrm{~B} \delta \times \mathrm{D} q\end{array}$ & $\begin{array}{l}\mathrm{K} \\
\mathrm{L} \\
\mathrm{M} \\
\mathrm{N}\end{array}$ & $\begin{array}{l}28 \\
72 \\
51 \\
46\end{array}$ & $\begin{array}{l}0 \cdot 43^{\mathrm{d}} \\
0 \cdot 43^{\mathrm{d}} \\
0 \cdot 42^{\mathrm{c}, \mathrm{d}} \\
0 \cdot 41^{\mathrm{b}-\mathrm{d}}\end{array}$ & $\begin{array}{l}0 \cdot 25 \\
0 \cdot 24 \\
0 \cdot 19 \\
0 \cdot 24\end{array}$ & $\begin{array}{r}0 \\
50 \\
25 \\
25\end{array}$ & $\begin{array}{l}25 \\
25 \\
25 \\
25\end{array}$ \\
\hline
\end{tabular}

* Means with one or more letters in common in superscript are not significantly different (Tukey-Kramer Method, Sokal and Rohlf 1981, p. 251) 
cent in the origin of their $\mathrm{X}$-linked loci but that were similar in their sets of autosomes. As seen in tables 2 and 3 , both reciprocal groups of $F_{2}$ females were similar in their oviposition-site preferences.

None of these experiments, therefore, provides any evidence that the $\mathrm{X}$ chromosome makes a statistically detectable contribution to variation in oviposition behaviour.

Table 2 Distribution of oviposition-site preferences of S64, $S 74$, and $F_{2}$ derived from crosses between these strains in Experiment 2. Based on individual flies that laid $>2$ eggs

\begin{tabular}{lllll}
\hline & \multicolumn{4}{c}{ Proportion of flies } \\
\cline { 2 - 5 }$P_{m}$ & S64 & S74 & A $^{*}$ & B $^{*}$ \\
\hline $0-0.20$ & 0.12 & 0.07 & 0.20 & 0.18 \\
$0 \cdot 21-0.40$ & 0.21 & 0.01 & 0.16 & 0.24 \\
$0.41-0.60$ & 0.29 & 0.03 & 0.22 & 0.19 \\
$0.61-0.80$ & 0.11 & 0.10 & 0.19 & $0 \cdot 18$ \\
$0.81-1.0$ & 0.27 & 0.79 & 0.23 & 0.21 \\
$P_{m}$ & 0.51 & 0.85 & 0.52 & 0.50 \\
$n$ & 113 & 72 & 96 & 117 \\
\hline
\end{tabular}

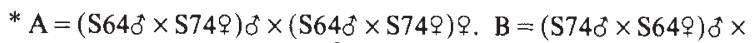
$\left(\mathrm{S} 740^{\circ} \times \mathrm{S} 64\right.$ 우용. A vs. B: $\chi^{2}=1 \cdot 74,4 \mathrm{df}, P>0.5$.

\section{Autosomal effects}

Groups of flies were produced in Experiment 1 that differed in the relative representation of S64and S74-derived autosomal genes but that did not differ with respect to X-linked loci. In three of these pairs, the groups varied significantly in oviposition-site preference. As seen in table 1, these pairs included groups $\mathrm{C}$ and $\mathrm{L}$ ( 25 per cent difference in origin of their autosomal genes), B and $\mathrm{K}$ (50 per cent difference), and $\mathrm{G}$ and $\mathrm{L}$ (50 per cent difference).

Besides demonstrating that the difference in oviposition-site preferences between strains S64 and S74 is determined primarily by autosomal loci, these experiments provide evidence that these loci do not always act in an additive, independent manner. In Experiment 1, the $F_{1}$ and flies obtained from backcrosses to S64 are similar to S64 in their average degree of preference for mushrooms, and flies produced from backcrosses of the $F_{1}$ to $S 74$ are actually more similar to S64 than to S74 (table 1, fig. 2). In Experiments 1 and 2, the $F_{2}$ derived from $\mathrm{S} 64 \times \mathrm{S} 74$ crosses resembled $\mathrm{S} 64$ in their average oviposition-site preference (tables 1 and 3 ). Thus, a striking aspect of the crosses between these two strains is the strong degree of dominance exhibited by the S64-derived alleles.

Other evidence suggests that strains S64 and S74 differ at a minimum of two loci that can interact in a non-additive fashion. In Experiment 1, the distribution of relative oviposition-site preference among S64 flies is significantly different from that of the $\mathrm{F}_{2}\left(\chi^{2}=20.2,6 \mathrm{df}, P<0.005\right)$ and from that of flies produced by backcrossing the $F_{1}$ to $S 64$ $\left(\chi^{2}=14 \cdot 7,6 \mathrm{df}, P<0.025\right)$. As can be seen in fig. 2 , this results from a significant deficiency of S64 flies laying from 0 per cent to 10 per cent of their eggs on mushrooms. Thus some flies with mixed S64S74 genomes prefer tomatoes as oviposition sites even more than do individuals of strain S64. This finding was corroborated in Experiment 4, in which more flies among the $F_{2}$ derived from $\mathrm{S} 64 \times \mathrm{S} 74$ crosses laid from 0 per cent to 20 per cent of their eggs on mushrooms than did S64 flies, although in this case the difference between the S64 and $F_{2}$ distributions was only marginally significant $\left(\chi^{2}=\right.$ $7 \cdot 88,4 \mathrm{df}, P<0 \cdot 1)$.

Additional evidence for the multi-locus nature of the difference between these strains is presented in fig. 2, where it can be seen that only 1 per cent of the $F_{2}$ and 7 per cent of the $F_{1} \times S 74$ flies laid from 80 per cent to 100 per cent of their eggs on mushrooms. This is far less than the $7 \cdot 8$ per cent and 15.5 per cent that would be expected for these two classes, respectively, if only a single locus affecting preference were segregating; expected values here are based on the observation that 30 per cent of the S74 and 1 per cent of the S64 flies laid from 80 per cent to 100 per cent of their eggs on mushrooms.

Table 3 Lack of $\mathrm{X}$ chromosome effect on oviposition-site preference in reciprocal $\mathrm{F}_{2}$ from crosses between strains GFS-B9 and GFS-M10 in Experiment 4. Based on individual females that laid $>10$ eggs

\begin{tabular}{|c|c|c|c|c|}
\hline Cross & $\begin{array}{l}\mathrm{X} \text { chromosomes } \\
\text { in } \mathrm{F}_{2}\end{array}$ & $n$ & $P_{m}^{*}$ & Std. Dev. \\
\hline  & $75 \% \mathrm{M} 10$ & 201 & $0 \cdot 77$ & $0 \cdot 32$ \\
\hline  & $75 \%$ B9 & 184 & $0 \cdot 80$ & $0 \cdot 28$ \\
\hline
\end{tabular}

* Distribution of oviposition-site preferences not significantly different $\left(\chi^{2}=0.01,1 \mathrm{df}, P=0.93\right.$; Kruskal-Wallis test used because data are bimodal, see fig. 3) 

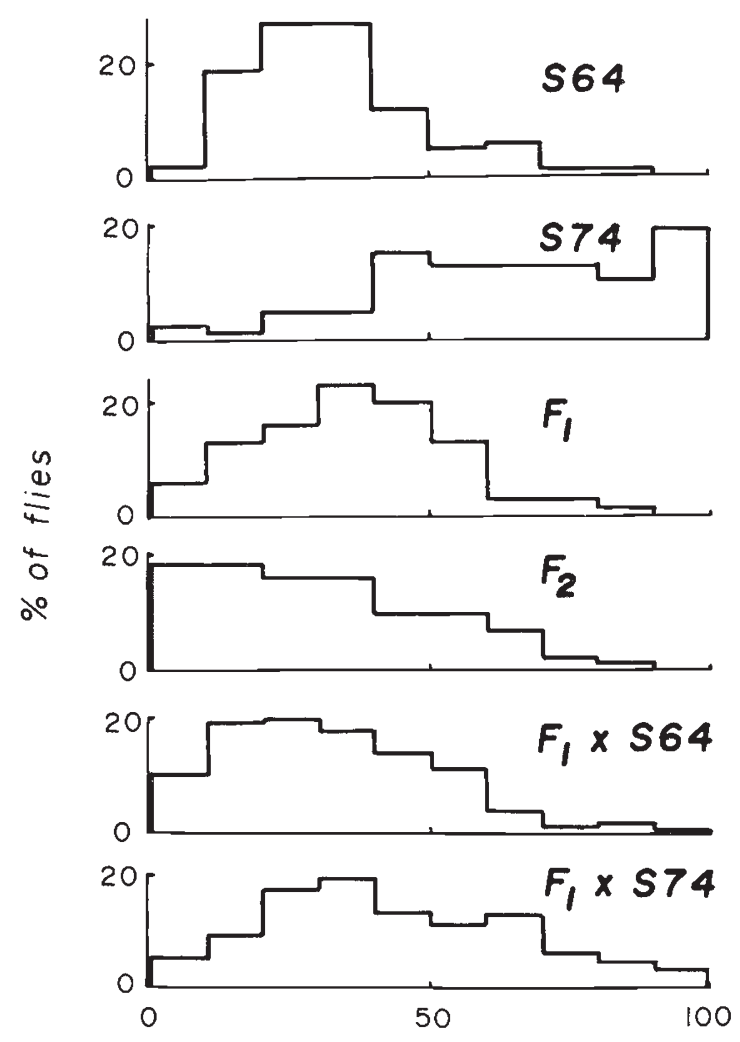

$\%$ eggs laid on mushrooms

Figure 2 Oviposition-site preference of strains S64, S74, and $F_{1}, F_{2}$ and backcrossed flies derived from crosses between these strains (Experiment 1). Flies within each category have similar complements of autosomes.

Despite the somewhat complex genetic basis for the difference in oviposition-site preference between strains S64 and S74, crosses involving other strains provided information that could lead eventually to the identification of at least one of the autosomal loci affecting this behaviour. Among strains collected at the Le Conte Creek site in the Great Smoky Mountains in 1984, a significant association was found between oviposition-site preference and the electrophoretically-determined genotype at the aconitase locus, an unmapped autosomal gene: 19 strains that were fixed for the M (medium electrophoretic mobility) electromorph laid an average of $0.37 \pm 0.03$ of their eggs on mushrooms, whereas for the three strains fixed for the $F$ (fast) electromorph this fraction was $0 \cdot 61 \pm 0 \cdot 07$. To pursue the possibility that one or more loci affecting oviposition behaviour are linked to aconitase, two strains (B9 and M10) from the Le Conte Creek site that differed in oviposition behaviour and aconitase mobility were used in Experiment 4.

In the initial survey of oviposition-site preference in the 1984 strains, B9 (which is fixed for the $\mathrm{M}$ electromorph of aconitase) and M10 (monomorphic for aconitase F) laid, respectively, 14 per cent and 68 per cent of their eggs on mushrooms. Experiment 4 was carried out about one year after the initial survey, at which time the percentages of eggs laid on mushrooms by strains B9 and M10 were 66 per cent and 82 per cent, respectively. (The reduced difference in oviposition behaviour between these strains and the greater preference of both for mushrooms as oviposition sites after one year in culture may result from the fact that both were maintained on mushroom-containing medium, in which females most prone to oviposit on mushrooms might be favoured.) $\mathrm{B} 9$ and $\mathrm{M} 10$ were crossed and the $\mathrm{F}_{1}$ were intercrossed to obtain an $F_{2}$ flies, in which the oviposition behaviour and aconitase genotypes were assayed. The correlation between ovipositionsite preference and aconitase persisted in the $F_{2}$, with the difference in preference among electrophoretically different flies being in the same direction as that found among the parental strains (fig. 3). $\mathrm{Aco}^{\mathrm{FF}}$ flies laid an average of 84 per cent of their eggs on mushrooms compared to 73 per cent for $\mathrm{Aco}^{\mathrm{MM}}$ flies. The oviposition behaviour of the FM heterozygotes was intermediate at 77 per cent. More striking than these average differences is the observation that about 15 per cent of the $A{ }^{M M}$ flies showed a very strong preference for tomatoes, whereas almost none of the $\mathrm{Aco}^{\mathrm{FF}}$ flies did. The overall distributions of preference differed significantly among flies as a function of their aconitase genotype (Kruskal-Wallis test; $\chi^{2}=$ $12 \cdot 3,2 \mathrm{df}, P=0 \cdot 002)$.

To summarise the results from crosses between strains S64, S74, B9, and M10, all of which were collected within $10 \mathrm{~km}$ of each other in the Great Smoky Mountains, no evidence for maternal/cytoplasmic or X-chromosomal effects on ovipositionsite preference was found in any of the experiments; all genetically-based differences among flies were found to have an autosomal basis.

Although only four isofemale strains from a single population were studied, the genetic basis for differences in oviposition behaviour appears to be at least moderately complex. Experiments 1 and 2 on strains S64 and S74 provided evidence that an epistatic interaction between two or more loci has a substantial effect, resulting in the production of flies that laid very few of their eggs on mushrooms. In addition, these two strains differed 


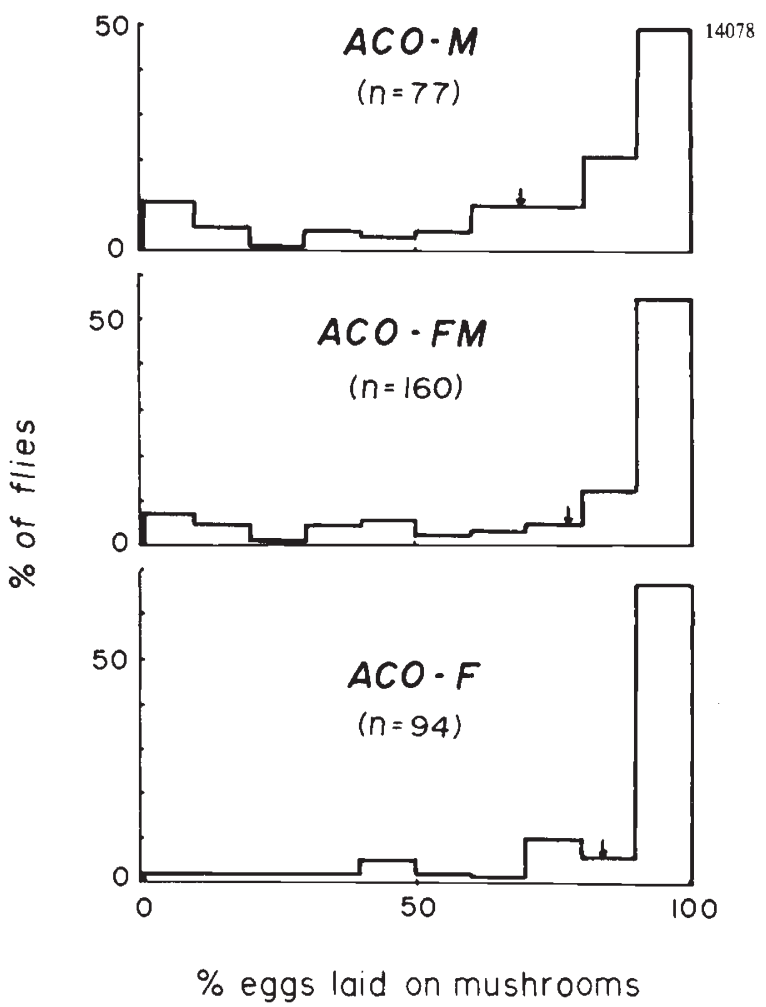

Figure 3 Oviposition-site preference of individual $F_{2}$ females derived from crosses between strains $\mathrm{B} 9$ and $\mathrm{M} 10$, classified by aconitase genotype. $\mathrm{M}$ and $\mathrm{F}$ indicate possession of allozymes of medium and fast mobility (Experiment 4). Arrows indicate mean preferences.

by at least one locus at which the S64-derived alleles were strongly dominant to those carried by S74. Thus, despite the fact that oviposition-site preference is a quantitative trait showing an approximately normal distribution among isofemale strains, some of the loci affecting this trait do not act in an additive, independent fashion. Thompson (1975) has pointed out that such normal distributions can also be produced by a small number of loci. Thus, the observation that a trait is normally distributed in a population does not necessarily mean that variation in that trait is governed by the action of many genes with small, additive effects.

An important evolutionary consequence of the finding that oviposition-site preference has a rather complex genetic basis is that it will be difficult to establish through linkage disequilibrium a genetic correlation between overall preference for a given breeding site and the genetically based ability of larvae to develop successfully there. The previously reported finding that different stages of the host-selection process are genetically independent in D. tripunctata renders the establishment of such linkage relationships even less likely (Jaenike, 1986). Thus, any genetic correlations between adult oviposition behaviour and larval performance would more likely be due to pleiotropy than to linkage.

The observation that oviposition-site preference depends upon interactions among loci means that founder events could occasionally lead to large changes in average preference, which in turn could play a role in genetic transilience (Templeton, 1980).

Finally, even though oviposition-site preference is governed by more than one locus, the discovery that at least one of these is linked to aconitase encourages the belief that it may eventually be possible to study the molecular and developmental basis of this ecologically important behaviour.

Acknowledgments This research was supported by National Science Foundation grant BSR 83-10141. The National Park Service kindly allowed me to collect flies in the Great Smoky Mountains. H. L. Carson, J. N. Thompson, T. Mitchell-Olds, and J. B. Spofford provided helpful comments on this paper.

\section{REFERENCES}

CARSON, H. L. AND OHTA, A. T. 1981. Origin of the genetic basis of colonizing ability. In Scudder, G. G. E. and Real, J. L. (eds.) Evolution Today, Carnegie-Mellon Univ., Pittsburgh, pp. 365-370.

ERWIN, T. L. 1982. Tropical forests: their richness in Coleoptera and other arthropod species. The Coleopterists Bulletin, 36 , 74-75.

ERWIN, T. L. 1983. Beetles and other insects of tropical forest canopies at Manaus, Brazil, sampled by insecticidal fogging. In Sutton, S. L., Whitmore, T. C. and Chadwick A. C. (eds.) Tropical Rain Forest: Ecology and Management, Blackwell, London, pp 59-75.

HUETTEL, M. D. AND BUSH, G. L. 1972. The genetics of host selection and its bearing on sympatric speciation in Procecidochares (Diptera: Tephritidae). Ent. Exp. Appl., 15, 465-480.

JAENIKE, J. 1982. Environmental modification of oviposition behavior in Drosophila. Amer. Natur., 119, 784-802.

JAENIKE, J. 1985. Genetic and environmental determinants of food preference in Drosophila tripunctata. Evolution, 39, 362-369.

JAENIKE, J. 1986. Genetic complexity of host-selection behavior in Drosophila. Proc. Natl. Acad. Sci., U.S.A. 83, 2148-2151.

JAENIKE, J. AND GRIMALDI, D. 1983. Genetic variation for host preference within and among populations of Drosophila tripunctata. Evolution, 37, 1023-1033.

JERMY, T. 1984. Evolution of insect/host plant relationships. Amer. Natur., 124, 609-630.

KNERER, G. AND ATWOOD, C. E. 1973. Diprionid sawflies: polymorphism and speciation. Science, 179, 1090-1099. 
LESLIE, J. F. AND DINGLE, H. 1983. A genetic basis of oviposition preference in the large milkweed bug, Oncopeltus fasciatus. Ent. Exp. Appl, 34, 215-220.

MILLER, J. R. AND STRICKLER, K. L. 1984. Finding and accepting host plants. In Bell, W. J. and Carde, R. T. (eds.) Chemical Ecology of Insects, Chapman and Hall, London, pp. 127-157.

ROSENTHAL, G. A. AND JANZEN, D. H. (eds.) 1979. Herbivores: Their Interaction with Secondary Plant Metabolites, Academic Press, New York.

SAS InSTITUTE INC. 1982. User's Guide, Cary, North Carolina.
TABASHNIK, B. E., WHEELOCK, H., RAINBOLT, J. D. AND WATT, W. B. 1981. Individual variation in oviposition preference in the butterfly, Colias eurytheme. Oecologia, 50, 225-230.

TEMPLETON, A. R. 1980. The theory of speciation via the founder principle. Genetics, 94, 1011-1038.

THOMPSON, J. N., JR. 1975. Quantitative variation and gene number. Nature, 258, 665-668.

WASSERMAN, S. S. AND FUTUYMA, D. J. 1981. Evolution of host plant utilization in laboratory populations of the southern cowpea weevil, Callosobruchus maculatus Fabricius (Coleoptera: Bruchidae). Evolution 35, 605-617.

Williams, C. B. 1960. The range and pattern of insect abundance. Amer. Natur., 94, 137-151 